\title{
Thin-film deposition and characterization of a Sn-deficient perovskite derivative $\mathrm{Cs}_{2} \mathrm{SnI}_{6}$
}

Bayrammurad Saparov, ${ }^{1,2}$ Jon-Paul Sun, ${ }^{3}$ Weiwei Meng, ${ }^{4}$ Zewen Xiao, ${ }^{4}$ Hsin-Sheng Duan, ${ }^{1}$ Oki Gunawan, ${ }^{5}$ Donghyeop Shin, ${ }^{1}$ Ian G. Hill, ${ }^{3}$ Yanfa Yan, ${ }^{4}$ David B. Mitzi ${ }^{1,2}$

${ }^{1}$ Department of Mechanical Engineering and Materials Science, Duke University, Durham, NC 27708, USA

${ }^{2}$ Department of Chemistry, Duke University, Durham, NC 27708, USA

${ }^{3}$ Department of Physics and Atmospheric Science, Dalhousie University, Halifax, Nova Scotia B3H 3J5, Canada

${ }^{4}$ Department of Physics and Astronomy and Center for Photovoltaics Innovation and Commercialization, The University of Toledo, Toledo, Ohio 43606, USA

${ }^{5}$ IBM T. J. Watson Research Center, PO Box 218, Yorktown Heights, NY 10598 USA

\section{Supporting Information}


Disclaimer: The information, data, or work presented herein was funded in part by an agency of the United States Government. Neither the United States Government nor any agency thereof, nor any of their employees, makes any warranty, express or implied, or assumes any legal liability or responsibility for the accuracy, completeness, or usefulness of any information, apparatus, product, or process disclosed, or represents that its use would not infringe privately owned rights. Reference herein to any specific commercial product, process, or service by trade name, trademark, manufacturer, or otherwise does not necessarily constitute or imply its endorsement, recommendation, or favoring by the United States Government or any agency thereof. The views and opinions of authors expressed herein do not necessarily state or reflect those of the United States Government or any agency thereof.

Solution deposition of $\mathrm{Cs}_{2} \mathrm{SnI}_{6}$ : $\mathrm{Cs}_{2} \mathrm{SnI}_{6}$ samples obtained by a gradual oxidation of $\mathrm{CsSnI}_{3}$ films ${ }^{1}$ go through several complex stages before all $\mathrm{CsSnI}_{3}$ peaks disappear from XRD patterns (Figure S1). In an attempt to optimize the reaction conditions, we have tried temperatures ranging from $105-125{ }^{\circ} \mathrm{C}$, and annealing times up to 3 days. The used temperature range was selected to reduce water vapor amount in the reaction medium and also to avoid higher temperatures, which can lead to the decomposition of $\mathrm{Cs}_{2} \mathrm{SnI}_{6}$. Irrespective of the selected annealing temperature, all films looked visibly heterogeneous, patchy and rough. Oxidation of $\mathrm{CsSnI}_{3}$ starts immediately upon exposure to ambient air, and evolution of $\mathrm{Cs}_{2} \mathrm{SnI}_{6}$ peaks are clearly noticeable. However, $\mathrm{CsSnI}_{3}$ peaks are present even after overnight annealing inside a drying oven and, only after 2 days at $120{ }^{\circ} \mathrm{C}$, do the $\mathrm{CsSnI}_{3}$ PXRD peaks completely disappear (Figure S1). In summary, controlling the oxidation procedure is very difficult as the oxidation of $\mathrm{CsSnI}_{3}$ to $\mathrm{Cs}_{2} \mathrm{SnI}_{6} \mathrm{Seems}$ to be occurring simultaneously with the decomposition of $\mathrm{Cs}_{2} \mathrm{SnI}_{6}$ and $\mathrm{CsSnI}_{3}$ into CsI and volatile Sn-based species, leading to inhomogeneous samples with poor coverage and impurities.

Compact $\mathrm{TiO}_{2}$ layer deposition: The compact $\mathrm{TiO}_{2}$ layer was deposited by spin coating at 2000 rpm for 1 min using a precursor solution of $0.23 \mathrm{M} \mathrm{Ti} \mathrm{(IV)} \mathrm{isopropoxide} \mathrm{(Sigma-Aldrich)} \mathrm{and}$ $0.013 \mathrm{M} \mathrm{HCl}$ in isopropanol (Aldrich). After spin coating, the $\mathrm{FTO} / \mathrm{c}-\mathrm{TiO}_{2}$ substrates were annealed in air at $520^{\circ} \mathrm{C}$ on a hot plate for $1 \mathrm{~h}$. 
XPS area quantification. For the calculation of compositions in Table S1, the following formulas were used, due to Auger peaks overlapping the Cs $3 d_{3 / 2}$ peaks in the $\mathrm{Mg} \mathrm{K} \alpha$ data. In order to evaluate carbon and oxygen content, the $\mathrm{C} 1 s$ and $\mathrm{O} 1 s$ percent values in Table $\mathrm{S} 1$ are listed as remaining peak area after sputtering or annealing.

Al Ka: $\quad \%_{x}=100 \times \frac{\left(\frac{A}{R S F}\right)_{x}}{\sum C S, S n, I\left(\frac{A}{R S F}\right)_{i}}$

$\operatorname{Mg~K\alpha }: \quad \%_{x}=100 \times \frac{\left(\frac{A}{R S F}\right)_{x}}{\left(\frac{A}{R S F}\right)_{C S 3 d 5 / 2}+\frac{1}{2} \sum S n, I\left(\frac{A}{R S F}\right)_{i}}$

Where $\mathrm{A}_{x}$ is the peak area of element $x, \mathrm{RSF}_{x}$ is the instrument relative sensitivity factor for element $x$. In the $\mathrm{Mg} \mathrm{K} \alpha$ spectra, the $\mathrm{Cs} 3 \mathrm{~d}_{3 / 2}$ peak is overlapped by an Auger peak and was not included in the intensity calculation, modifying the formula in the denominator.

Photoelectron Spectroscopy (XPS, UPS, IPES). The $\mathrm{Cs}_{2} \mathrm{SnI}_{6}$ films were studied as-loaded and after receiving short ( 5 seconds and 10 seconds) sputtering treatments. The as-loaded films have a slightly Cs-rich and I-poor composition, indicative of CsI on the film surfaces (Table S1). A similar Cs-rich and I-poor composition has been noted for the related $\mathrm{Cs}_{3} \mathrm{Sb}_{2} \mathrm{I}_{9}{ }^{2}$ and the observed deviations from the expected stoichiometry may possibly be attributed to surface beam damage and/or volatility of $\mathrm{SnI}_{4} / \mathrm{SbI}_{3}$.

In addition to the shift of the onset to lower binding energy by $\sim 0.3 \mathrm{eV}$ with sputtering, there is also a loss of DOS in the 4-9 eV binding energy region for the sputtered $\mathrm{Cs}_{2} \mathrm{SnI}_{6}$ films. This behavior is also similar to the reported observations for the sputtered $\mathrm{Cs}_{3} \mathrm{Sb}_{2} \mathrm{I}_{9}$ films. ${ }^{2}$ The close up region of the valence band maximum of the as-loaded and sputtered $\mathrm{Cs}_{2} \mathrm{SnI}_{6}$ samples shows an emergence of states extending lower than $1.5 \mathrm{eV}$ in the latter. These states are presumably due to defects induced by sputtering. 


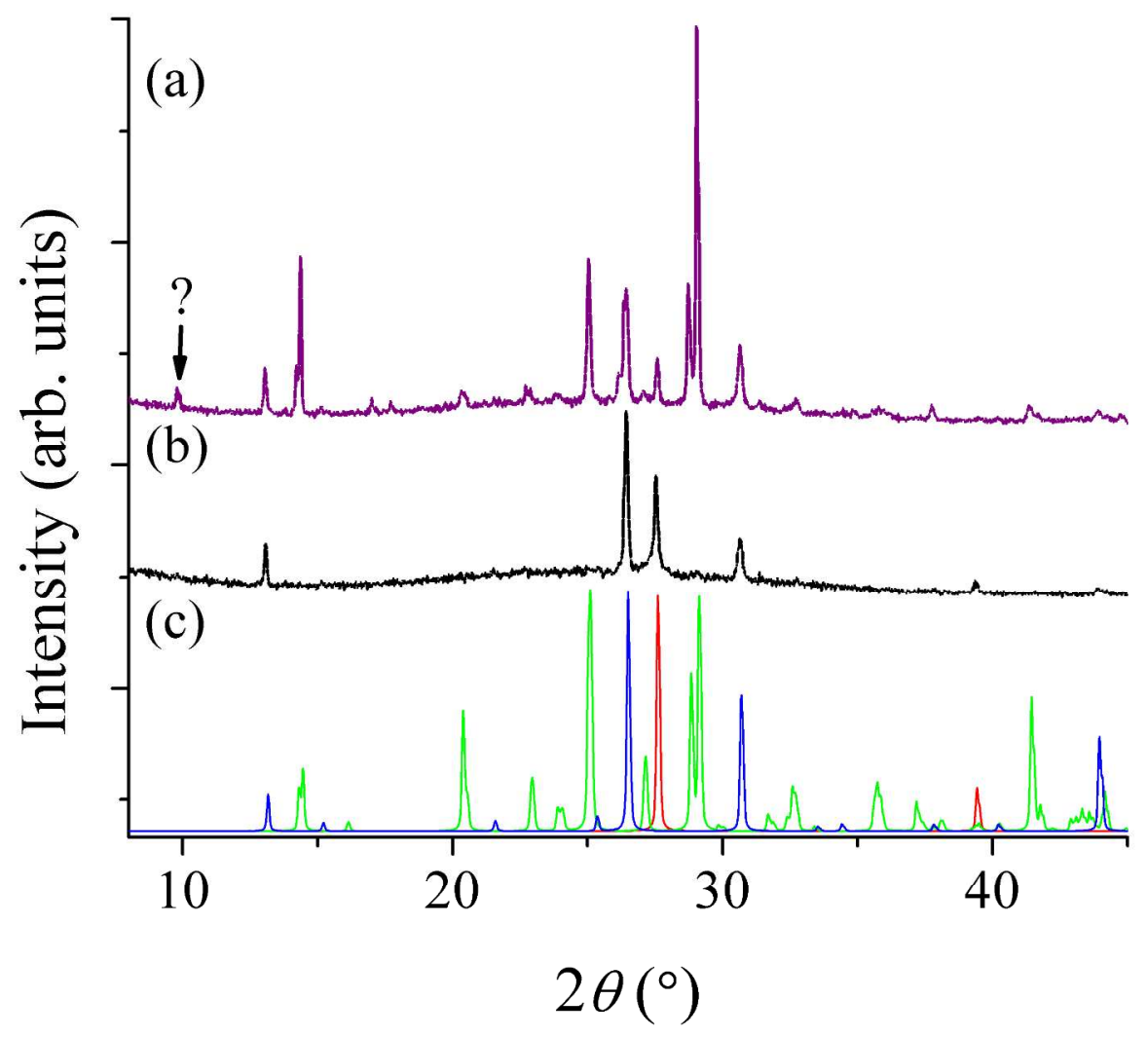

Figure S1. X-ray diffraction patterns of samples obtained by a gradual oxidation of the $\mathrm{CsSnI}_{3}$ films ${ }^{1}$ inside a drying oven: (a) after 1 hour at $120{ }^{\circ} \mathrm{C}$, the rough films are visibly heterogeneous and contain regions of leftover $\mathrm{CsSnI}_{3}$, newly formed $\mathrm{Cs}_{2} \mathrm{SnI}_{6}, \mathrm{CsI}$, and an unidentified impurity peak (labeled with a question mark); (b) after 2 days at $120^{\circ} \mathrm{C}$, the patchy films exhibit only $\mathrm{Cs}_{2} \mathrm{SnI}_{6}$ and CsI peaks. (c) The simulated patterns for CsI (red), $\mathrm{CsSnI}_{3}$ (green), and $\mathrm{Cs}_{2} \mathrm{SnI}_{6}$ (blue) are also provided. 


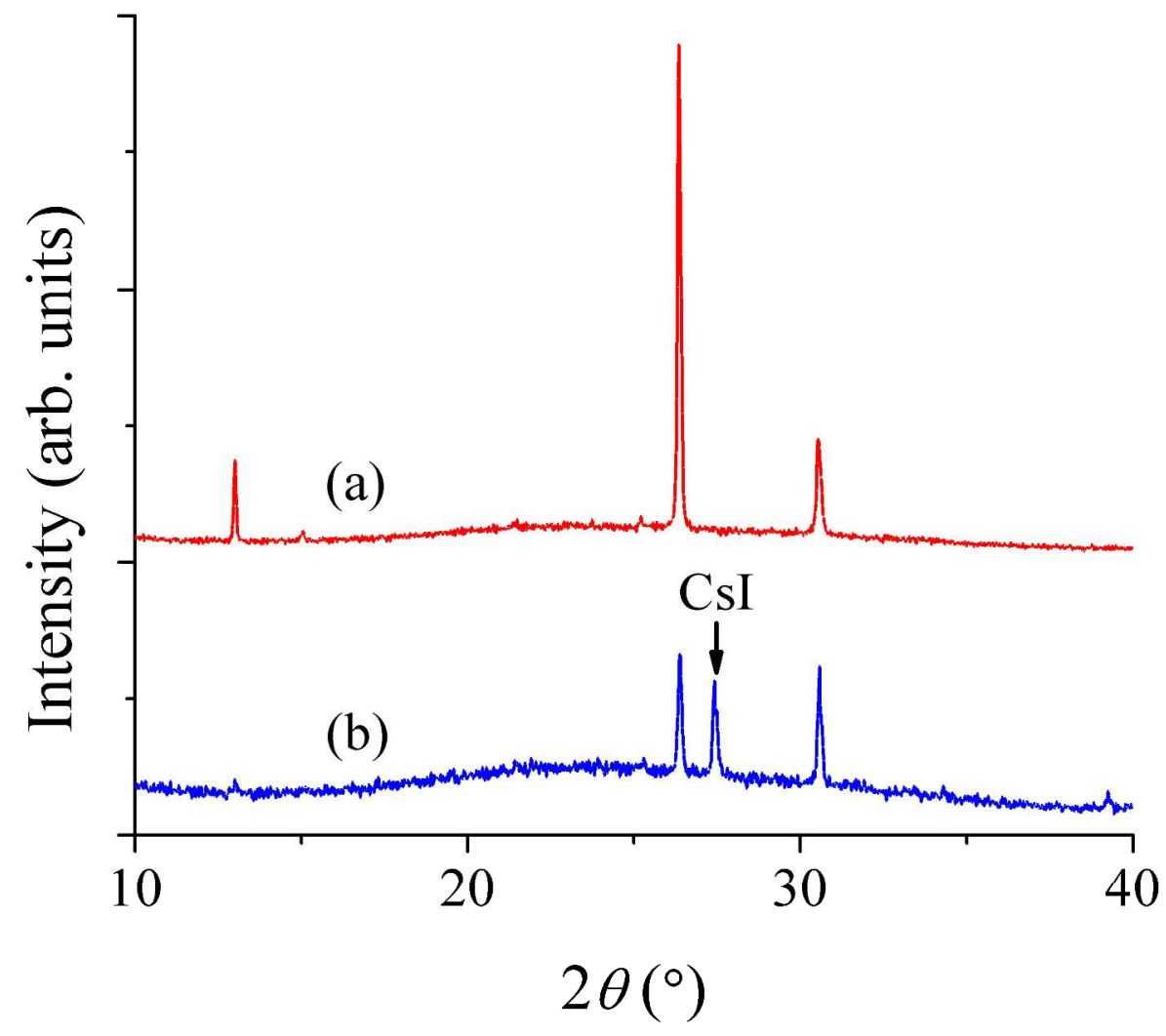

Figure S2. (a) X-ray diffraction pattern of a bulk $\mathrm{Cs}_{2} \mathrm{SnI}_{6}$ sample obtained using the method described by Lee et al. ${ }^{3}$ All peaks are successfully assigned to the cubic $\mathrm{Cs}_{2} \mathrm{SnI}_{6}$ structure ( $\mathrm{Fm}$ $3 m$ ). (b) After 5 days in ambient air with relative humidity of 25-50\%, the emergence of a strong CsI impurity peak is observed. 


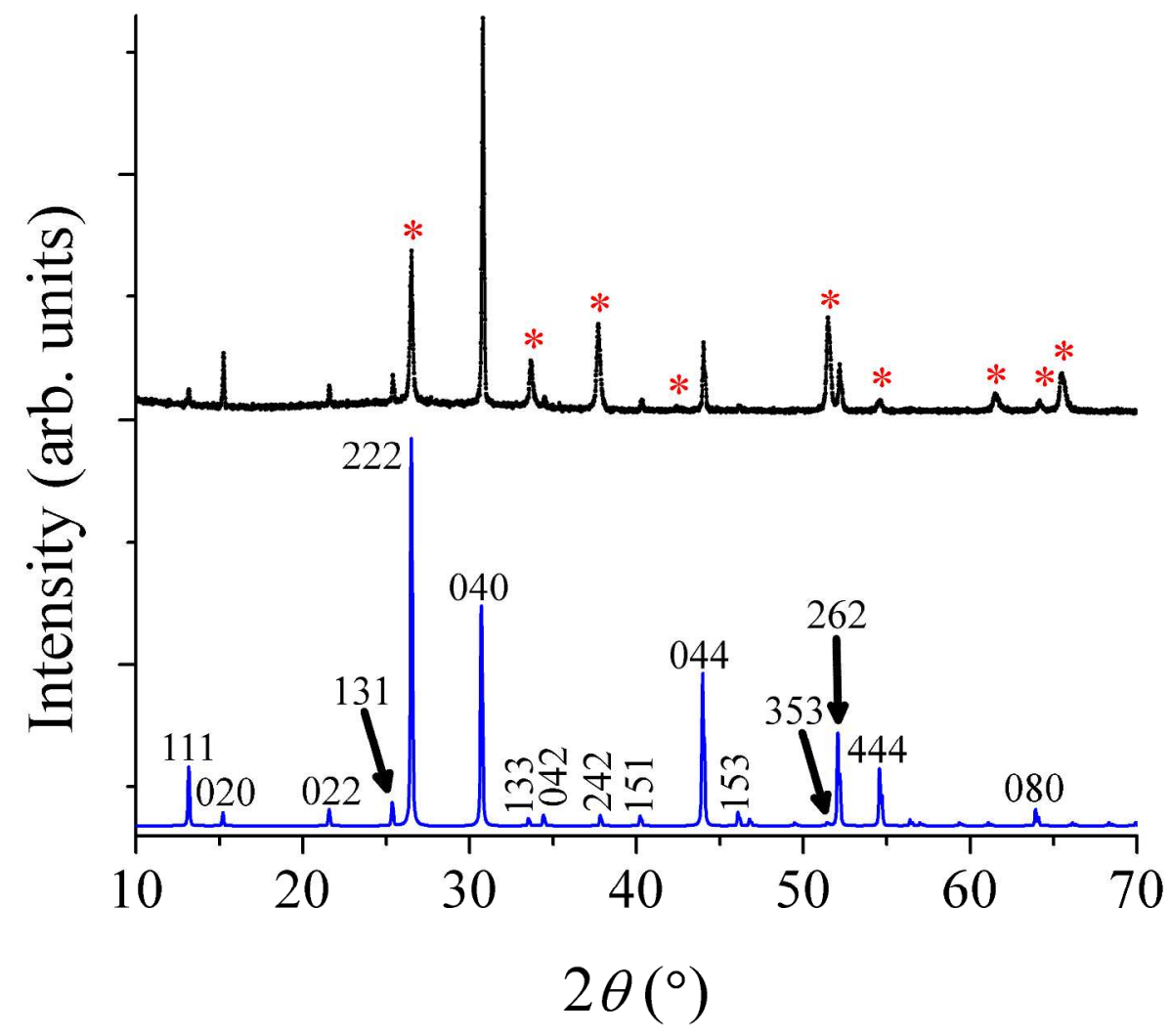

Figure S3. X-ray diffraction pattern of a $\mathrm{Cs}_{2} \mathrm{SnI}_{6}$ film (black, top) deposited on a FTO/c- $\mathrm{TiO}_{2}$ substrate shows a different preferred orientation compared to that of $\mathrm{Cs}_{2} \mathrm{SnI}_{6}$ films deposited on glass slides. Here, increased $\langle 020\rangle$ peak intensities are noticeable, in contrast to the more $\langle 111\rangle$ oriented films obtained on glass substrates. Peaks that belong to the FTO substrate are labeled with a red star. The simulated PXRD pattern of $\mathrm{Cs}_{2} \mathrm{SnI}_{6}$ with labeled peaks is also provided (blue, bottom). 


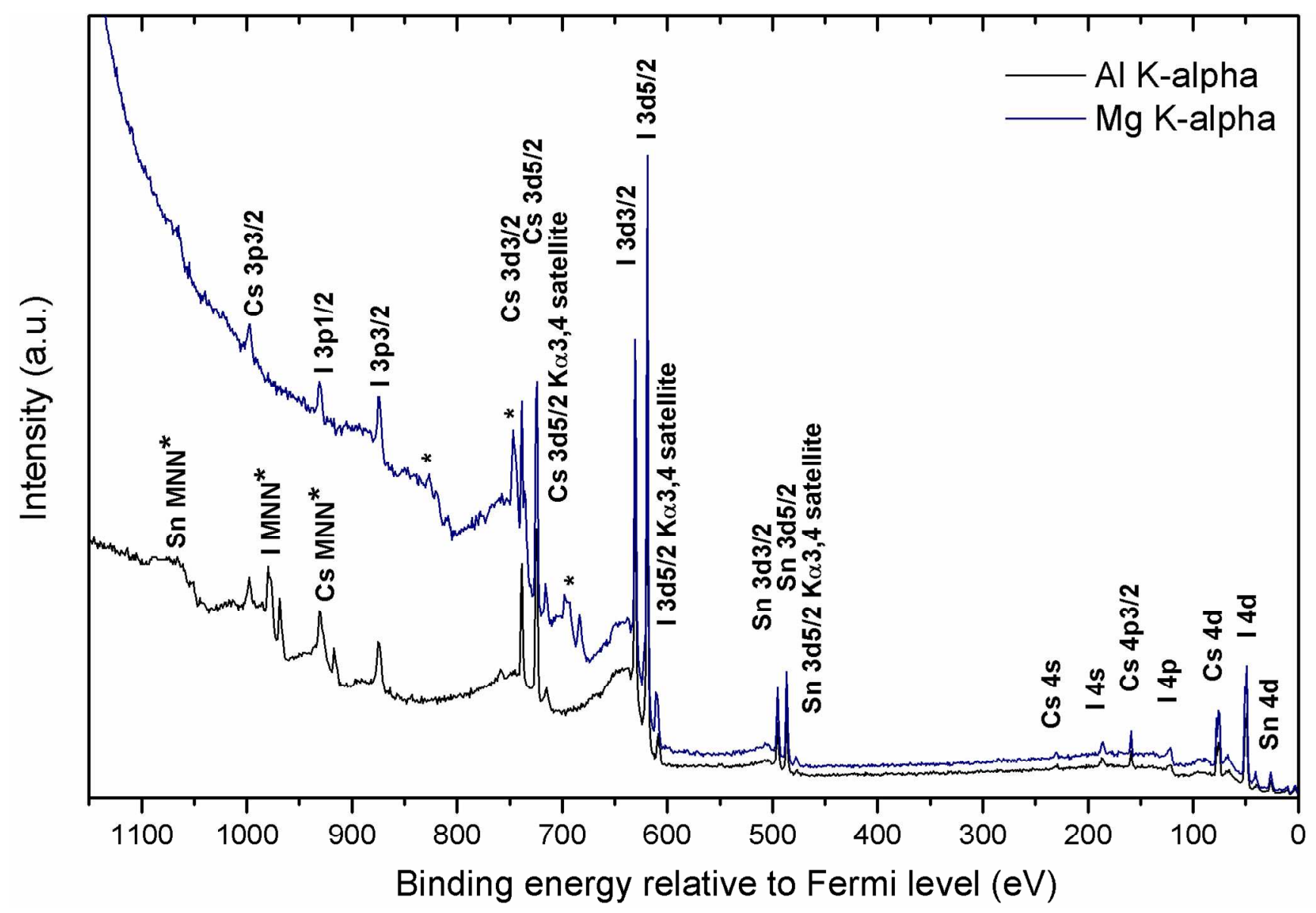

Figure S4. XPS Al and Mg Ka survey scans of the $200 \mathrm{~nm} 10$ s sputtered film. The peaks indicated with $\operatorname{star}(*)$ on the $\mathrm{Mg} \mathrm{K \alpha}$ spectrum correspond to the Auger MNN peaks identified on the Al K $\alpha$ spectrum. 

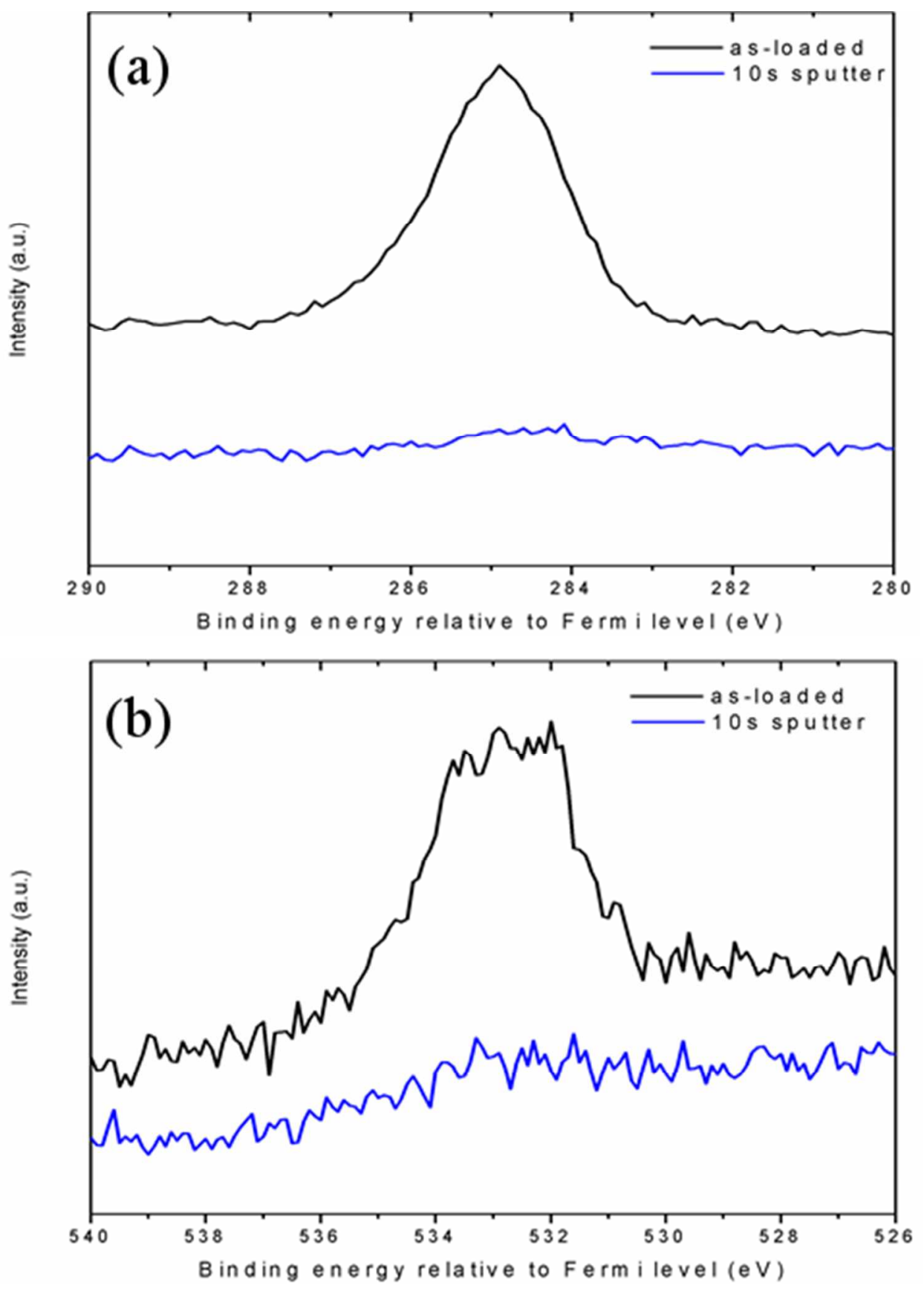

Figure S5. XPS Al Ka close-up view of the (a) C $1 s$ and (b) O $1 s$ peaks of the $200 \mathrm{~nm}$ sample showing before and after sputtering for 10s. 


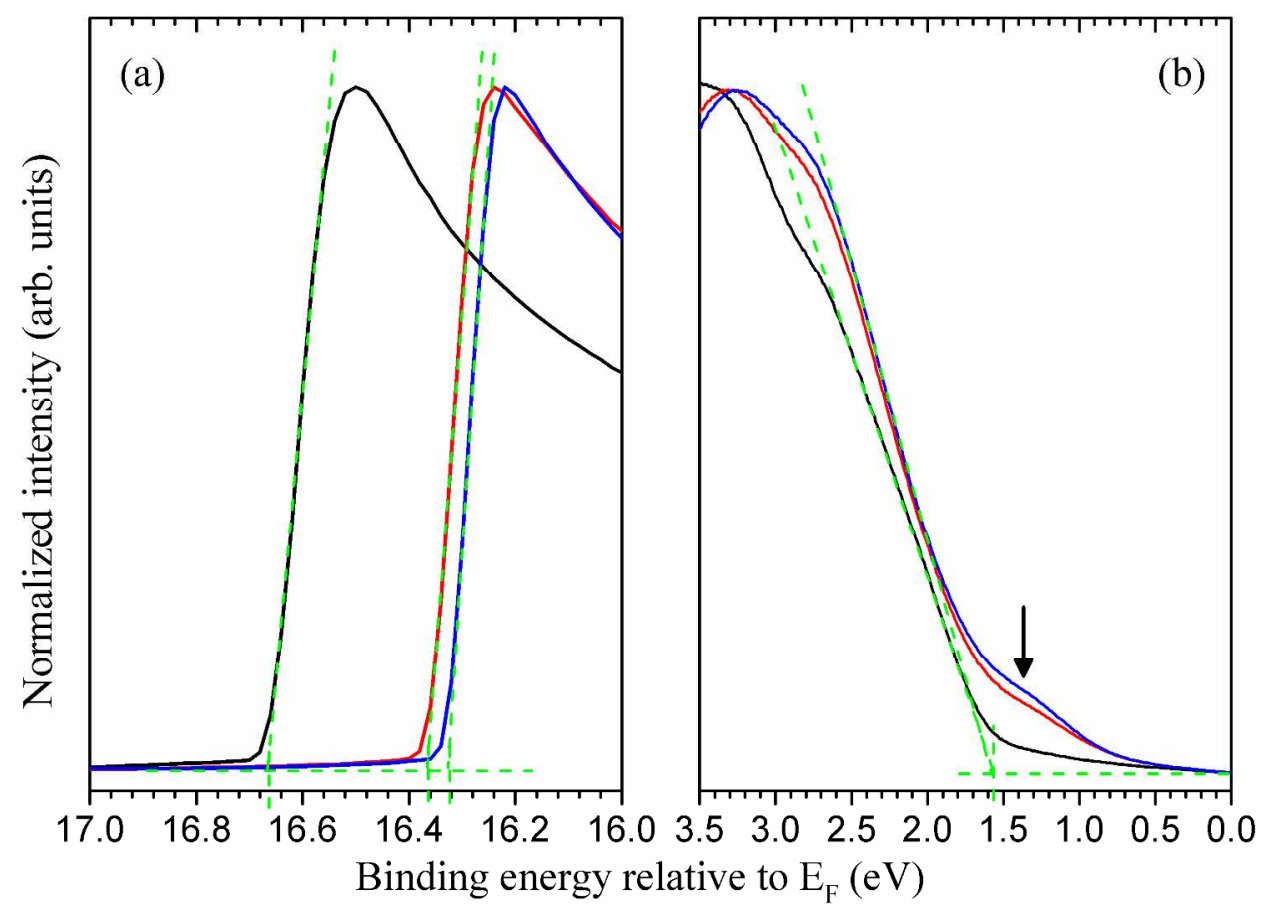

Figure S6. (a) He I emission onset for the as-loaded (black curve), $5 \mathrm{sec}$ (red curve) and $10 \mathrm{sec}$ (blue curve) sputtered $200 \mathrm{~nm} \mathrm{Cs}_{2} \mathrm{SnI}_{6}$ films. The onset after sputtering shifts to lower binding energy by $\sim 0.3 \mathrm{eV}$. (b) UPS He I VBM for the as-loaded (black curve), $5 \mathrm{sec}$ (red curve) and 10 sec (blue curve) sputtered $200 \mathrm{~nm} \mathrm{Cs}_{2} \mathrm{SnI}_{6}$ films. The intercept of a tangent line fitted to the leading edge of the spectra and the baseline determine the VBM position (green dashed lines). The increase in DOS in the $1.5-1 \mathrm{eV}$ region (arrow) are attributed to defects induced by sputtering. 

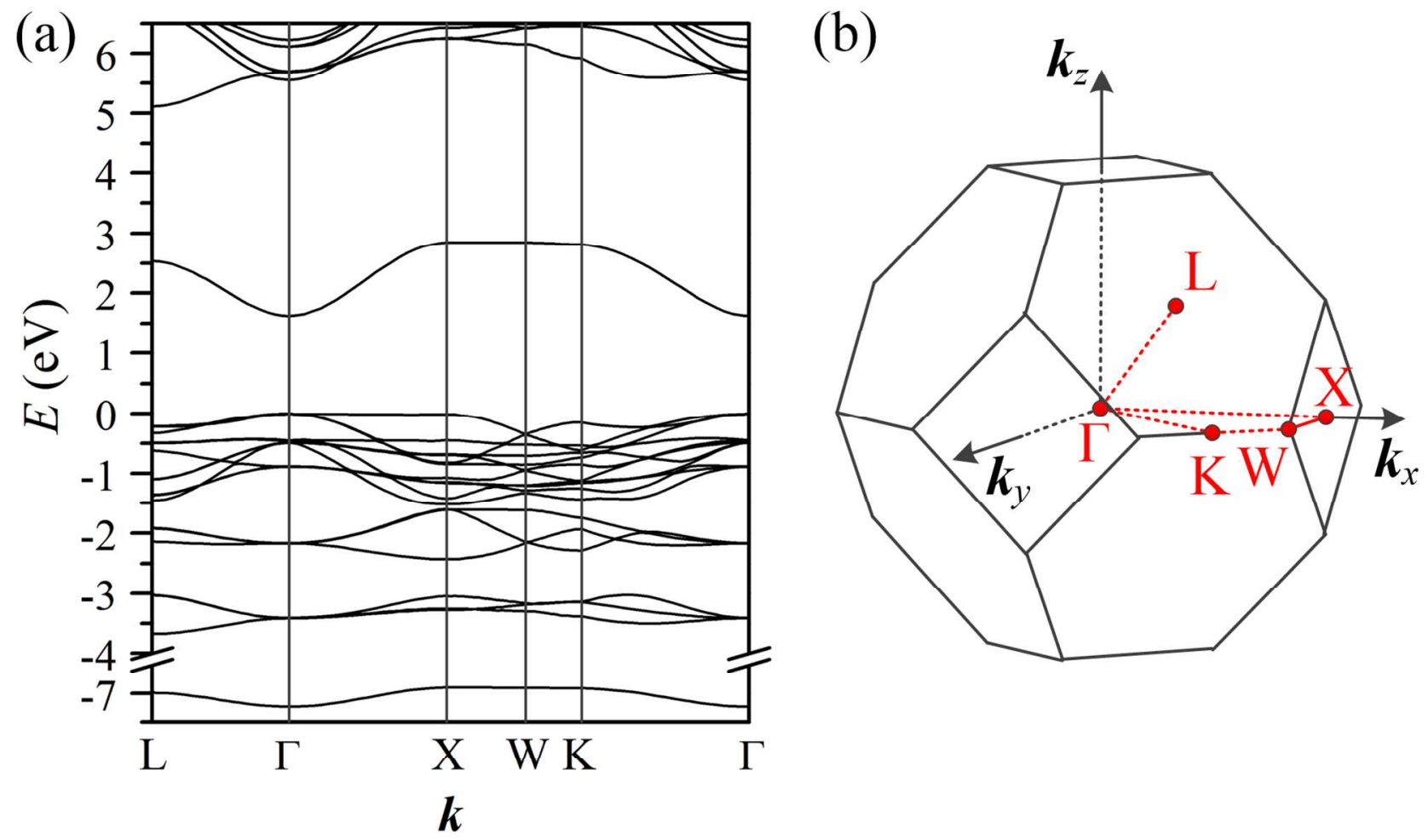

Figure S7. (a) Calculated band structure of $\mathrm{Cs}_{2} \mathrm{SnI}_{6}$ using the HSE hybrid functional with $37.0 \%$ of Hartree-Fock exact exchange. (b) The Brillouin zone and high-symmetry $k$-points for $\mathrm{Cs}_{2} \mathrm{SnI}_{6}$. 
Table S1. Elemental compositions (atomic \%) of $\mathrm{Cs}_{2} \mathrm{SnI}_{6}$ films based on XPS data before and after receiving sputtering treatments, and after an in-vacuum annealing.

\begin{tabular}{|c|c|c|c|c|c|c|c|c|c|c|}
\hline & & $\begin{array}{l}\text { XPS } \\
\text { source } \\
\end{array}$ & $\begin{array}{r}\text { Cs } \\
3 d_{3 / 2} \\
\end{array}$ & $\begin{array}{r}\text { Cs } \\
3 d_{5 / 2} \\
\end{array}$ & $\begin{array}{r}\text { Sn } \\
3 d_{3 / 2} \\
\end{array}$ & $\begin{array}{r}\text { Sn } \\
3 d_{5 / 2} \\
\end{array}$ & $\begin{array}{r}I \\
3 d_{3 / 2}\end{array}$ & $\begin{array}{r}I \\
3 d_{5 / 2} \\
\end{array}$ & $\begin{array}{r}C \\
1 \mathrm{~s} \\
\end{array}$ & $\begin{array}{r}0 \\
1 s \\
\end{array}$ \\
\hline Expected & & & 22.2 & 22.2 & 11.1 & 11.1 & 66.7 & 66.7 & - & - \\
\hline \multirow{6}{*}{$200 \mathrm{~nm}$} & \multirow{2}{*}{ as loaded } & $\mathrm{Al}$ & 26.8 & 26.6 & 10.7 & 10.6 & 62.7 & 62.7 & 100.0 & 100.0 \\
\hline & & $\mathrm{Mg}$ & - & 26.7 & 11.4 & 11.4 & 62.0 & 62.0 & 100.0 & 100.0 \\
\hline & \multirow{2}{*}{5 s sputter } & $\mathrm{Al}$ & 28.9 & 28.7 & 10.8 & 10.7 & 60.4 & 60.4 & 26.4 & 53.1 \\
\hline & & $\mathrm{Mg}$ & - & 29.1 & 11.5 & 11.5 & 59.5 & 59.5 & 29.1 & 33.0 \\
\hline & \multirow{2}{*}{ 10s sputter } & $\mathrm{Al}$ & 28.7 & 28.5 & 11.6 & 11.5 & 59.8 & 59.8 & 8.5 & 19.1 \\
\hline & & $\mathrm{Mg}$ & - & 29.5 & 12.0 & 12.0 & 58.5 & 58.5 & 12.0 & 24.9 \\
\hline \multirow{2}{*}{$300 \mathrm{~nm}$} & \multirow{2}{*}{ as loaded } & $\mathrm{Al}$ & 27.0 & 26.9 & 10.6 & 10.5 & 62.5 & 62.5 & 100.0 & 100.0 \\
\hline & & $\mathrm{Mg}$ & - & 26.6 & 11.3 & 11.3 & 62.1 & 62.1 & 100.0 & 100.0 \\
\hline
\end{tabular}




\section{References}

(1) Zhang, J.; Yu, C.; Wang, L.; Li, Y.; Ren, Y.; Shum, K. Energy barrier at the N719dye/CsSnI 3 interface for photogenerated holes in dye-sensitized solar cells. Sci. Rep. 2014, 4, 6954.

(2) Saparov, B.; Hong, F.; Sun, J.-P.; Duan, H.-S.; Meng, W.; Cameron, S.; Hill, I. G.; Yan, Y.; Mitzi, D. B. Thin-Film Preparation and Characterization of $\mathrm{Cs}_{3} \mathrm{Sb}_{2} \mathrm{I}_{9}$ : A Lead-Free Layered Perovskite Semiconductor. Chem. Mater. 2015, 27, 5622-5632.

(3) Lee, B.; Stoumpos, C. C.; Zhou, N.; Hao, F.; Malliakas, C.; Yeh, C.-Y.; Marks, T. J.; Kanatzidis, M. G.; Chang, R. P. H. Air-Stable Molecular Semiconducting Iodosalts for Solar Cell Applications: $\mathrm{Cs}_{2} \mathrm{SnI}_{6}$ as a Hole Conductor. J. Am. Chem. Soc. 2014, 136, 15379-15385. 